\title{
Optimalisasi Jaringan Komputer Menggunakan VPN Concentrator Dengan Bonding Pada PT Maxindo Mitra Solusi Jakarta
}

\author{
Yudi Supriadi ${ }^{1}$, Irwan Agus Sobari ${ }^{2}$, Richky Faizal Amir ${ }^{3}$ \\ ${ }^{1,2}$ Teknik Informatika, STMIK Nusa Mandiri, Jl. Jl. Jatiwaringin No. 2, Jakarta Timur, Jakarta \\ ${ }^{3}$ Teknologi Informasi, Universitas Bina Sarana Informatika Jl. Kramat Raya no. 98 Pusat, Indonesia e-mail: \\ 1yudisupriadi9a@gmail.com, 라wan.igb@nusamandiri.ac.id, ${ }^{3}$ richky.cfj@bsi.ac.id
}

\begin{tabular}{ccc}
\hline Diterima & Direvisi & Disetujui \\
$15-04-2021$ & $28-05-2021$ & $03-06-2021$ \\
\hline
\end{tabular}

\begin{abstract}
Abstrak - Pada jaringan internet kualitas suatu koneksi ditentukan oleh beberapa faktor diantaranya throughput bandwidth yang berjalan karena banyak sedikitnya bandwidth akan mempengaruhi akses bagi pengguna baik itu untuk browsing, streaming, download dan upload. Hal tersebut bukan hanya terjadi pada traffic yang menuju ke internet, melainkan terjadi juga pada jaringan VPN dimana apabila banyak user yang menggunakan traffic data VPN dapat menyebabkan akses menjadi lambat. Terlebih lagi apabila pada suatu jaringan memiliki 2 link internet yang seharusnya kedua link tersebut dapat digunakan secara bersamaan. Ada beberapa parameter yang dapat digunakan untuk meningkatkan kapasitas bandwidth diantaranya adalah Bonding. Bonding merupakan teknologi yang memungkinkan agregasi lebih dari satu interface ethernet dan menggabungkan kedalam satu link virtual sehingga kita akan mendapatkan throughput bandwith yang lebih besar. Faktor lain yang berpengaruh terhadap kualitas suatu koneksi diantaranya adalah topologi. Pemilihan topologi terutama pada jaringan VPN yang memiliki banyak node diperlukan topologi yang menerapkan sebuah perangkat jaringan yang bertugas menjadi concentrator sehingga jaringan VPN terpusat pada concentrator tersebut. Perangkat yang digunakan sebagai router concentrator adalah Mikrotik.
\end{abstract}

Kata Kunci: VPN, Bonding, Maxindo

Abstract - On the internet, the quality of a connection is determined by several factors, including the running bandwidth throughput because the amount of bandwidth will affect access for users, be it for browsing, streaming, downloading, and uploading. This not only happens to traffic going to the internet but also happens to VPN networks where if many users use VPN data traffic it can cause slow access. Moreover, if a network has 2 internet links, the two links should be used simultaneously. Several parameters can be used to increase bandwidth capacity, including Bonding. Bonding is a technology that allows the aggregation of more than one ethernet interface and combines them into one virtual link so that we will get a greater bandwidth throughput. Another factor that affects the quality of a connection is topology. Topology selection, especially on VPN networks that have many nodes, requires a topology that implements a network device that is in charge of being a concentrator so that the VPN network is centralized on the concentrator. The device used as a concentrator router is Mikrotik.

Key Word: VPN, Bonding, Maxindo

\section{PENDAHULUAN}

Perkembangan teknologi jaringan komputer menunjukkan peningkatan yang sangat pesat seiring dengan semakin meningkatnya kebutuhan akan terhubungnya lokasi-lokasi yang terpisah secara jarak namun ingin tetap berkomunikasi dan berbagi akses. Kebutuhan untuk tetap berkomunikasi antar cabang dirasakan besar kebutuhannya untuk level perusahaan. Perusahaan yang memiliki banyak cabang tentunya ingin semua cabang saling terhubung dan dapat bertukar informasi dan memiliki akses yang internet stabil. Menurut ((Kuswanto \& Rahman, 2019) kebutuhan internet saat ini semakin dominan, jika terjadi permasalahan pada router akan memyebabkan banyak gangguan yang menyebabkan kerugian pada pengguna internet. Tidak ada provider internet yang bisa menjamin $100 \%$ tidak akan mengalami gangguan internet pada usernya ((Rifai \& Supriyanto, 2017).

Oleh sebab itu, dibutuhkan infrastruktur jaringan komputer yang handal agar semua cabang dapat terhubung ke kantor pusat. Dalam komunikasi dan berbagi informasi antara kantor pusat dengan kantor cabang yang tersebar diberbagai lokasi, dibutuhkan jaringan internet yang stabil dan sistematis, sehingga jaringan yang berbeda dapat terhubung dalam satu jaringan komputer secara aman dan luas. Menurut (Rahman \& Rahman, 2020) infrastruktur menggunakan kabel untuk komunikasi jarak jauh kurang cocok di terapkan di Indonesia. Infrstuktur jaringan komputer yang terpasang 
nantinya akan menjadi prototype untuk pembangunan dan pengembangan sistem jaringan sehingga memudahkan untuk perancangan dan pengembangan berikutnya. Menurut (Hidayatulloh \& Wahyudin, 2019) "Hal ini juga dapat memberi petunjuk bagi para pengguna jaringan agar tidak salah dalam menggunakan layanan yang tersedia pada sebuah jaringan. Pembangunan infrastruktur jaringan ini berdasarkan pada mekanisme pembangunan jaringan secara virtual yaitu Virtual Private Network (VPN)".

Pada jaringan VPN PT Maxindo Mitra Solusi saat ini sudah terkonfigurasi VPN untuk menangani kebutuhan tersebut, hanya saja pada saat ini sering terdapat permasalahan diantaranya throughput VPN yang tidak maksimal karena kebutuhan akses yang tinggi, kesulitan dalam mengelola jaringan VPN baik pada troubleshooting maupun ketika ada penambahan cabang baru, dan penggunaan link backup yang tidak efektif. Remote access menggunakan VPN atau aplikasi remote membutuhkan jaringan internet yang stabil ((Doni \& Lesmono, 2018).

Salah satu permasalahan yang sering terjadi di masyarakat yaitu masalah kecilnya bandwidth yang diperoleh, karena banyak sedikitnya bandwidth akan mempengaruhi akses bagi pengguna, baik itu untuk download, atau browsing. Jika bandwidth yang didapat sedikit maka koneksi menjadi lambat, sehingga user merasa kesal dan tidak puas. Oleh karena itu bandwidth pada user harus ditingkatkan kapasitas bandwidthnya, dengan Link Agregation yaitu penggabungan lebih dari satu interface. Menurut (NIKMAH \& Prihanto, 2017) "Pada mikrotik menggunakan metode Bonding untuk menggabungkan lebih dari satu interface kedalam satu link virtual sehingga akan mendapatkan throughput bandwidth yang lebih besar".

Hal tersebut bukan hanya terjadi pada traffic yang menuju ke internet, melainkan terjadi juga pada jaringan VPN dimana apabila banyak user yang menggunakan traffic data VPN dapat menyebabkan akses menjadi lambat. Jaringan komputer yang baik juga harus memperhatikan keamanan agar terhindar dari orang-orang yang tidak bertanggung jawab (Sobari, 2015). Menurut (Doni, 2019) kapasitas bandwidth yang diberikan ke pengguna internet harus optimal sehingga pelanggan tidak merasa kecewa. Karena dalam industri 4.0 ini hampir semua instansi baik pemerinta maupun swasta membutuhkan internet baik dan stabil ((Rahman et al., 2020).

Berdasarkan uraian diatas maka penulis mengusulkan untuk melakukan implementasi dan optimalisasi terhadap jaringan VPN PT Maxindo Mitra Solusi dengan menggunakan konsep VPN concentrator dengan link aggregation (Bonding) agar jaringan VPN dapat dikelola dengan mudah karena semua site terhubung ke satu concentrator beserta throughput yang didapatkan lebih maksimal karena penerapan bonding. Perusahaan-perusahaan yang berkembang membutuhkan transfer data dan internet yang sangat cepat untuk menunjang jalannya proses transaksi dan manajemen perusahaan tersebut agar selalu realtime serta efisien (Zuhri \& Sobari, 2017).

\section{METODE PENELITIAN}

Teknik penumpulan data yang dilakukan oleh penulis dalam mencari dan mengumpulkan data serta mengelola informasi yang diperlukan menggunakan metode sebagai berikut

\section{a. Observasi}

Pada metode ini penulis melakukan pengamatan langsung terhadap jaringan VPN yang digunakan untuk mendapatkan data dan informasi yang berkaitan dengan permasalahan yang ada pada salah satu perusahaan Swasta di Provinsi DKI Jakarta yaitu PT Maxindo Mitra Solusi yang beralamat di Jalan Cendrawasih Raya No 61 Cengkareng Jakarta Barat

\section{b. Wawancara Penulis}

Melakukan tanya jawab secara langsung kepada narasumber yaitu Pak Erick Setiawan yang menjabat sebagai Supervisor Network Analyst PT Maxindo Mitra Solusi untuk mendapatkan informasi yang berkaitan dengan metode VPN yang digunakan, hardware yang diperlukan, system dan infrastruktur jaringan VPN yang digunakan di perusahaan ini.

\section{c. Studi Pustaka}

Untuk mendapatkan informasi yang terkait dengan permasalahan yang akan di analisa, penulis mencari informasi mengenai topik yang sedang dibahas dari jurnal atau literatul terkait serta mengumpulkan bahan-bahan yang ada hubunganya dengan pembahasan yang penulis bahas

Metode yang digunakan dalam penelitian ini digunakan adalah metode System Devlopment Life Cycle (SDLC) model sekuensial linier atau sering disebut juga sebagai model waterfall.

\section{Analisa Kebutuhan}

Untuk bisa membuat simulasi optimasi jaringan VPN ini maka dibutuhkan beberapa aplikasi dan hardware pendukung seperti, gns3 sebagai simulator jaringan, virtualbox sebagai virtualisasi mesin router mikrotik dan vnc viewer sebagai aplikasi remote ke server serta koneksi internet untuk koneksi team viewer dengan server, dan hardware yang dibutuhkan yaitu laptop sebagai media simulasi.

\section{Desain}

Untuk desain yang akan digunakan pada simulasi jaringan VPN concentrator ini menggunakan virtual mesin dengan operating sistem Mikrotik sebagai router concentrator dan router VPN. Topologi yang digunakan adalah topologi star dimana dari masingmasing cabang terhubung ke satu concentrator dengan menggunakan dua link tunnel yang berjalan secara round robin sehingga membentuk jaringan baru. Routing untuk jaringan internal diarahkan kepada router concentrator dan untuk throughput VPN didapatkan berdasarkan jumlah througput dari kedua link. 


\section{Testing}

Testing dilakukan dengan melakukan konfigurasi link VPN pada router concentrator dan setiap cabang yang akan terhubung. Setelah semuanya terhubung dilakukan konfigurasi link aggregation untuk masingmasing tunnel yang sudah dikonfigurasikan, data atau traffic internal yang dikirim oleh user akan melewati link aggregation tersebut dan router concentrator, pada simulasi ini penulis menggunakan software atau aplikasi network simulator yaitu GNS3.

\section{Implementasi}

Untuk melakukan optimalisasi jaringan menggunakan VPN concentrator dengan link aggregation ini diperlukan konfigurasi tunneling baik pada router concentrator dan router VPN. Link tunneling dikonfigurasi sebanyak 2 tunnel untuk kebutuhan link aggregation sehingga throughput VPN lebih maksimal.

\section{HASIL DAN PEMBAHASAN}

\section{Sistem Jaringan Berjalan}

Setelah melakukan observasi kepada supervisor PT Maxindo Mitra Solusi terdapat kendala pada jaringan VPN dengan topologi yang saat ini berjalan diantaranya:

a. Dengan topologi mesh network administrator kesulitan dalam hal troubleshoot karena banyaknya node ataupun link yang harus dilakukan pengecekan ketika terjadinya kendala.

b. Jaringan VPN tidak stabil disebabkan oleh througput link FO yang tidak dapat memenuhi kebutuhan VPN.

c. Pada saat penambahan site baru network administrator kesulitan dikarenakan harus menambahkan konfigurasi disemua router.

d. Failover tidak berjalan sehingga apabila link FO terkendala, koneksi VPN terkendala down dan network administrator harus mengkonfigurasikan semua link VPN secara manual.

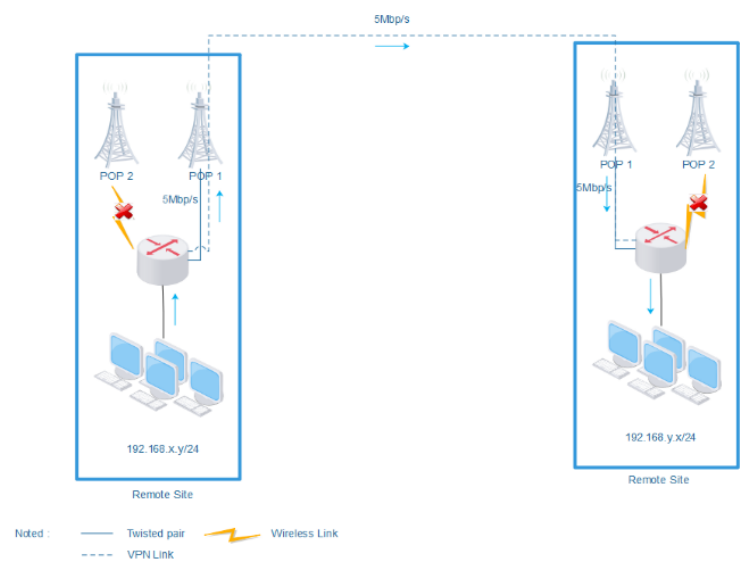

Sumber : Data Penelitian(2021)

Gambar 1. Topologi Case

Dari gambar tersebut dapat dilihat bahwa througput VPN hanya berdasarkan pada link FO sedangkan ada link wireless yang seharusnya dapat dioptimalkan dengan cara menggunakan link tersebut juga sebagai link VPN sehingga througput yang dihasilkan dapat lebih maksimal

\section{Topologi Jaringan}

Dengan penerapan topologi mesh seperti yang diterapkan pada topologi jaringan VPN PT Maxindo Mitra Solusi saat ini maka diperlukan konfigurasi yang sangat kompleks agar tidak terjadi kendala, pada permasalahan yang dibahas di BAB sebelumnya. Pada penulis mendesain topologi usulan agar jaringan VPN berjalan dengan semestinya dan tidak ada kendala yang akan berdampak pada user.

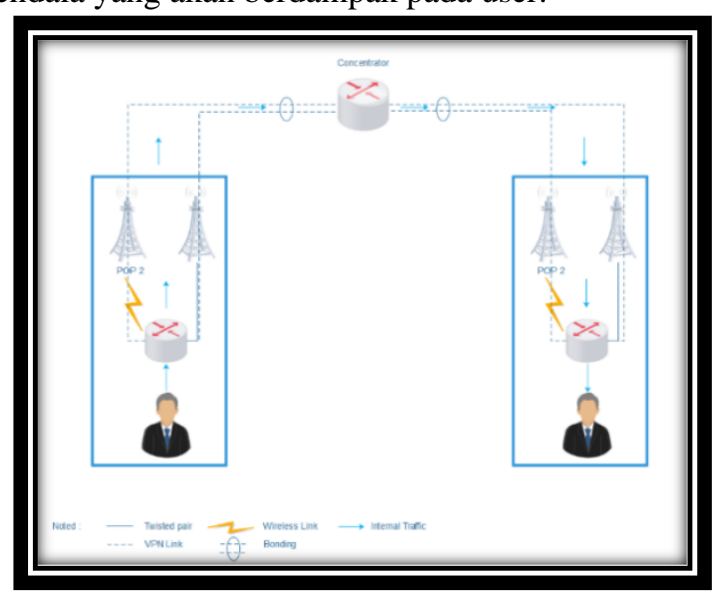

Sumber : Data Penelitian(2021)

Gambar 2. Topologi Usulan

Dengan penerapan topologi star dengan penambahan 1 router sebagai concentrator maka seluruh link VPN akan mengarah ke concentrator sehingga apabila user akan melakukan akses terhadap jaringan VPN maka traffic akan mengarah ke concentrator terlebih dahulu menggunakan link VPN yang sudah dikonfigurasi bonding antara link VPN via FO dan link VPN via wireless seperti pada gambar diatas. 
Througput jaringan VPN akan maximal dikarenakan kedua link digunakan dimana traffic yang berjalan menggunakan metode round robin. Apabila terjadi gangguan pada link FO arah lalu lintas data akan otomatis pindah ke link wireless begitupun sebaliknya, failover ini ditangani oleh bonding menggunakan mii monitoring.

\section{Skema Jaringan}

Pada jaringan VPN PT Maxindo Mitra Solusi menggunakan satu perangkat router yang digunakan sebagai concentrator VPN sehingga semua traffic VPN akan diarahkan terlebih dahulu ke concentrator tersebut menggunakan eoip tunnel. Dari masingmasing site dikonfigurasikan 2 link eoip tunnel yaitu eoip tunnel via link FO, dan eoip tunnel via link wireless. Kedua link tersebut dijadikan interface bonding agar kedua link dapat berjalan secara bersamaan dan througput jaringan VPN dapat dimaksimalkan.

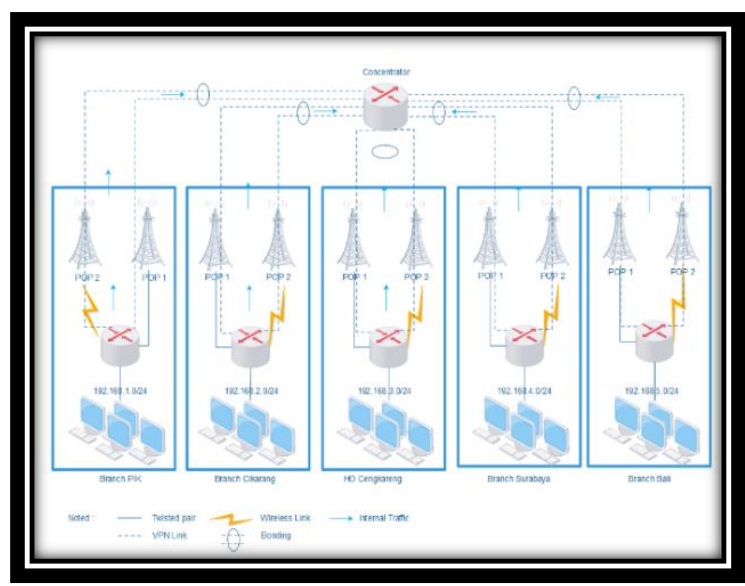

Sumber : Data Penelitian(2021)

Gambar 3. Arsitektur Jaringan VPN

Pada gambar tersebut dijelaskan bahwa terdapat terdapat 6 router yaitu router concentrator, router branch PIK, router branch Cikarang, router branch cengkareng, router branch surabaya, dan router branch bali. Setiap router yang terinstall mempunyai peran yang berbeda.

\section{Pengujian Jaringan Awal}

Untuk pengujian awal menggunakan simulator GNS3 dengan kondisi dimana link VPN yang digunakan hanya menggunakan link FO beserta tidak dikonfigurasikannya failover. Berikut konfigurasi jaringan VPN pada tahap pengujian jaringan awal. a) Topologi

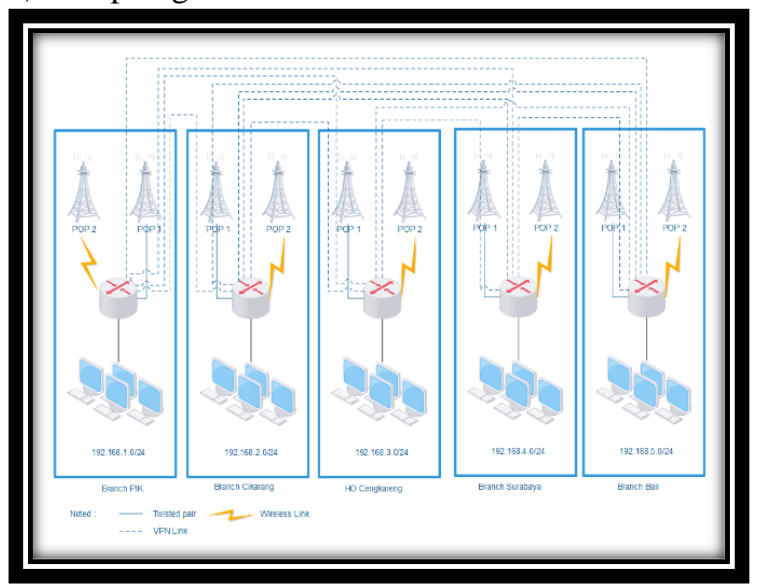

Sumber : Data Penelitian(2021)

Gambar 4. Topologi Awal

Dengan topologi mesh seperti gambar tersebut network administrator kesulitan dalam hal troubleshoot maupun penambahan site dikarenakan banyaknya node ataupun link yang harus dilakukan pengecekan ataupun penambahan.

b) Konfigurasi link tunnel

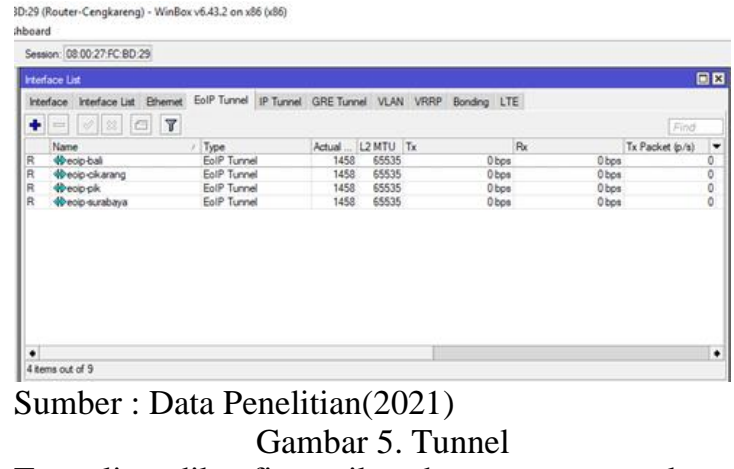

Tunneling dikonfigurasikan hanya menggunakan 1 link dengan tunnel mengarah ke semua router sehingga membentuk topologi mesh. Pada gambar IV.43 merupakan contoh interface tunnel yang berada pada router cengkareng, pada router tersebut dapat dilihat bahwa router melakukan tunneling ke semua site dan kondisi link yang digunakan hanya 1 link.

c) Pengujian Failover

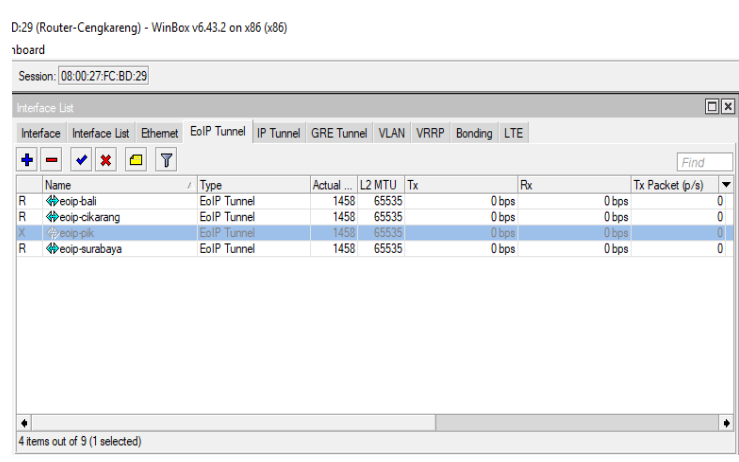

Sumber : Data Penelitian(2021)

Gambar 6. Failover Disable Tunnel Awal 
Penulis melakukan pengetesan failover dengan melakukan ping dari router cengkareng ke user yang berada dibawah jaringan site PIK dimana dilakukan pengetesan dengan men disable tunnel sehingga link tunnel tersebut down. Setelah dilakukan disable, penulis mengamati ping dari router cengkareng ke user disite PIK dan didapatkan hasil sebagai berikut :

\section{Sumber : Data Penelitian(2021)}

Gambar 7. Ping User Site Pik Awal

Dari gambar tersebut dijelaskan bahwa ketika link tunnel down maka koneksi VPN ke user pun terpantau down dan jaringan lumpuh total. Pada saat seperti ini network administrator harus mengkonfigurasikan ulang semua jaringan VPN dengan menggunakan link wireless.

\section{d) Throughput VPN}

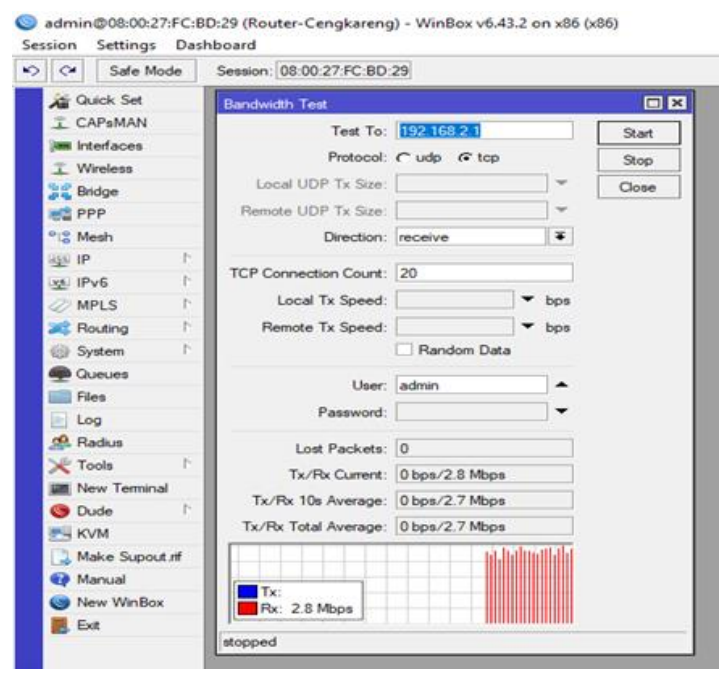

Sumber : Data Penelitian(2021)

Gambar 8. Throughput VPN Awal

Pada Gambar tersebut dijelaskan bahwa througput VPN hanya diangka 3Mbps sesuai kapasitas dari link FO, sedangkan pada router tersebut ada link wireless yang dapat digunakan untuk memaksimalkan link VPN.

\section{e) Routing}

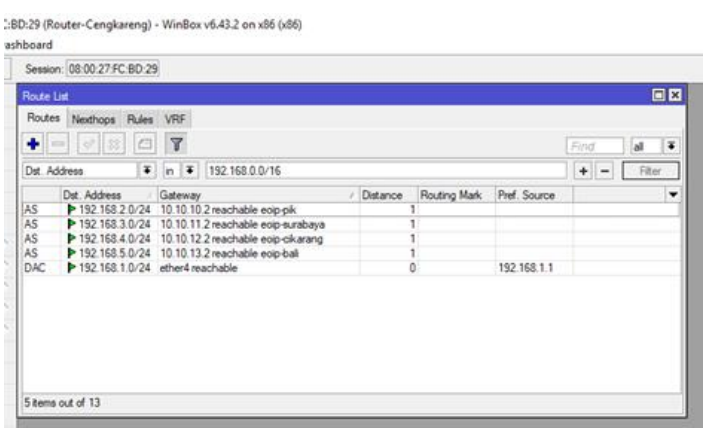

Sumber : Data Penelitian(2021)

Gambar 9. Routing Awal

Dikarenakan eoip tunnel langsung mengarah ke masing-masing sehingga konfigurasi routing harus dikonfigurasikan juga ke masing-masing site dari setiap router. Pada gambar tersebut merupakan contoh konfigurasi routing yang berada pada router cengkareng dimana konfigurasi routing harus dilakukan ke masing-masing site.

\section{f) Pengujian Jaringan Akhir}

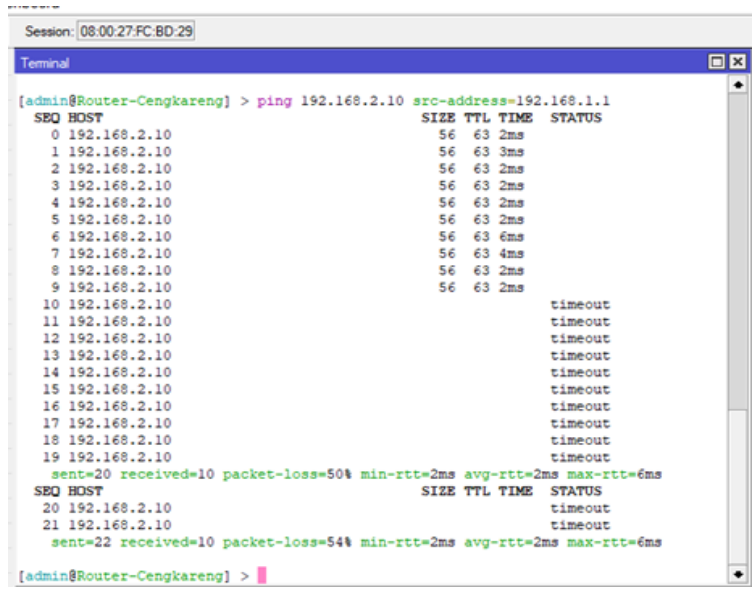

Pada pembahasan pengujian jaringan awal bahwa adanya bottleneck pada jaringan VPN beserta tidak berjalannya sistem failover apabila link FO terkendala down. Hal tersebut disebabkan oleh througput link FO yang tidak maximal dan adanya link wireless yang tidak dimanfaatkan dengan baik sehingga berpengaruh ke throuhgput VPN beserta sistem failover. Pada topologi sebelumnya dengan penerapan topologi mesh juga menyebabkan network administrator kesulitan dalam pengecekan apabila terjadinya troubleshoot maupun penambahan site dikarenakan banyaknya node maupun link yang harus dilakukan pengecekan atau penambahan site.

Berikut tahap pemecahan masalah dan pengujian jaringan akhir:

1) Perubahan topologi

Untuk menangani masalah topologi, diterapkan topologi star pada jaringan VPN PT Maxindo Mitra Solusi agar fleksibel dan membantu mempermudah network administrator dalam mendeteksi masalah maupun penambahan site.

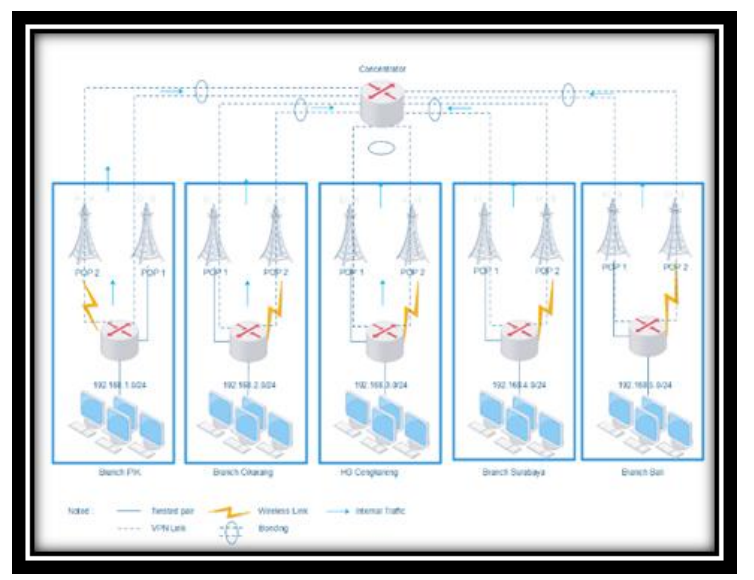

Sumber : Data Penelitian(2021) Gambar 10. Topologi Star VPN 
Pada gambar tersebut dijelaskan bahwa dilakukan penambahan satu perangkat router yang digunakan sebagai concentrator VPN sehingga semua traffic VPN akan diarahkan terlebih dahulu ke concentrator tersebut menggunakan eoip tunnel. Pengecekan dan pendeteksian masalahpun akan lebih mudah dikarenakan network administrator hanya perlu melakukan pengecekan pada satu node yaitu router concentrator. Hal tersebut disebabkan oleh router concentrator dapat mendeteksi semua link maupun traffic jaringan VPN.

\section{2) Konfigurasi 2 link tunnel}

Dikonfigurasikan 2 link tunnel dari masing-masing site dimana 1 link menggunakan link FO dan 1 link mengunakan link wireless dikarenakan kedua link tersebut akan digunakan.

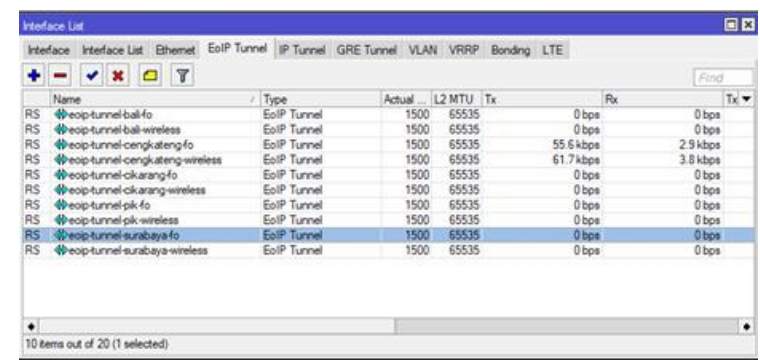

Sumber : Data Penelitian(2021)

Gambar 11. Eoip Tunnel

Pada gambar tersebut dapat dilihat bahwa dari masing-masing site terkoneksi 2 tunnel ke concentrator baik dari site cengkareng, site pik, site surabaya, site cikarang maupun site bali

\section{3) Konfigurasi Bonding dan Failover}

Agar kedua link tunnel dapat digunakan maka dikonfigurasikan interface bonding sehingga jalur VPN diarahkan ke interface bonding. Pada bonding ini juga dikonfigurasikan failover menggunakan MII (Media Independent Interface) monitoring sehingga apabila terjadinya kendala pada salah satu link maka traffic akan berjalan pada link yang aktif.

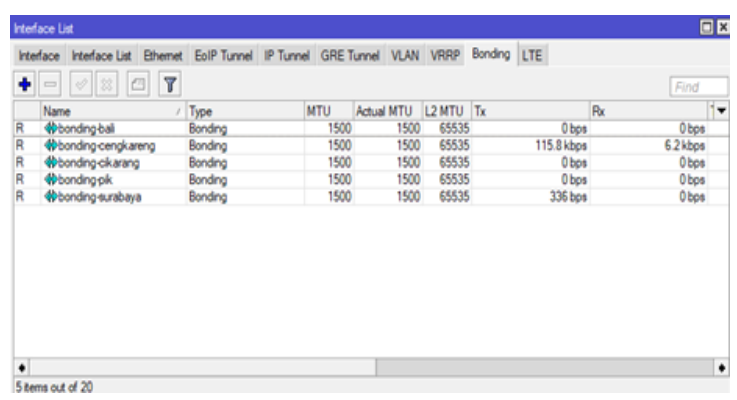

Sumber : Data Penelitian(2021)

Gambar 12. Bonding

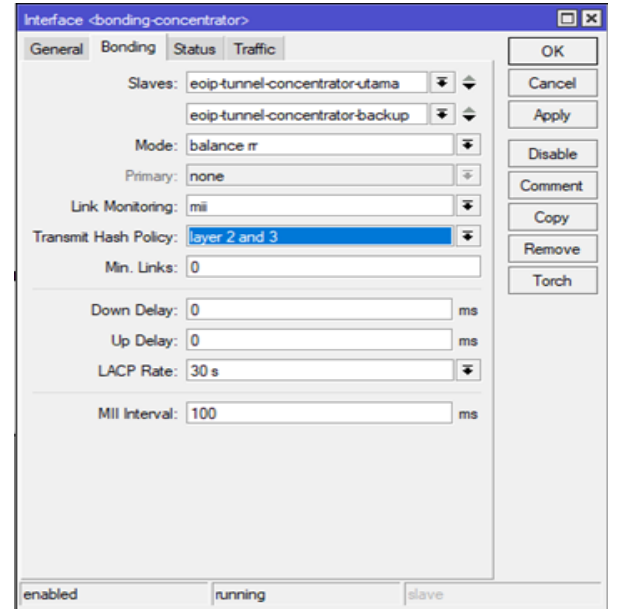

Sumber : Data Penelitian(2021)

Gambar 13. Konfigurasi Bonding

4) Pengecekan througput link VPN

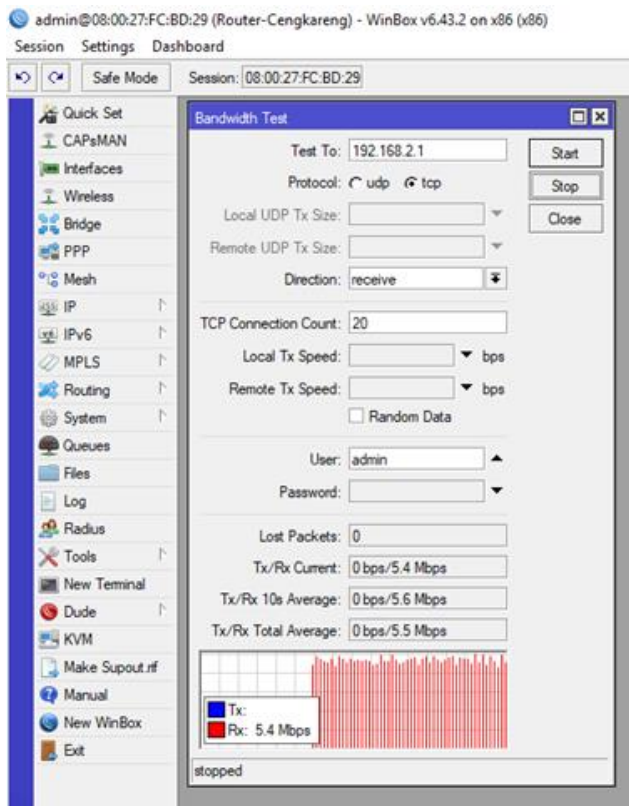

Sumber : Data Penelitian(2021)

Gambar 14. Througput VPN ke PIK

Pada gambar tersebut dijelaskan bahwa through put link VPN dapat mencapai angka 6Mbps dimana untuk link FO dan link wireless sendiri hanya berkapasitas masing-masing 3Mbps.

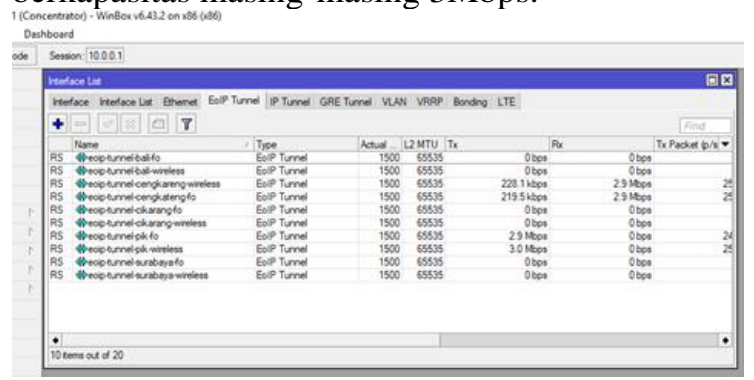

Sumber : Data Penelitian(2021)

Gambar 15. Traffic VPN 
Dari sisi traffic juga dapat dilihat bahwa kedua link sudah berjalan secara bersamaan dengan traffic dari masing-masing link adalah 3Mbps.

\section{5) Pengecekan Failover}

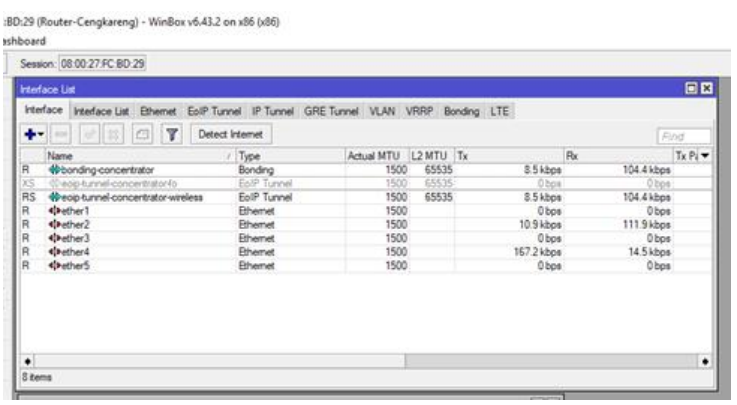

Sumber : Data Penelitian(2021)

Gambar 16. Failover disable tunnel

Penulis melakukan pengetesan failover dengan melakukan ping dari router cengkareng ke user yang berada dibawah jaringan site PIK dimana dilakukan pengetesan dengan mendisable link FO sehingga link tunnel tersebut down. Setelah dilakukan disable, penulis mengamati ping dari router cengkareng ke user disite PIK dan didapatkan hasil sebagai berikut :

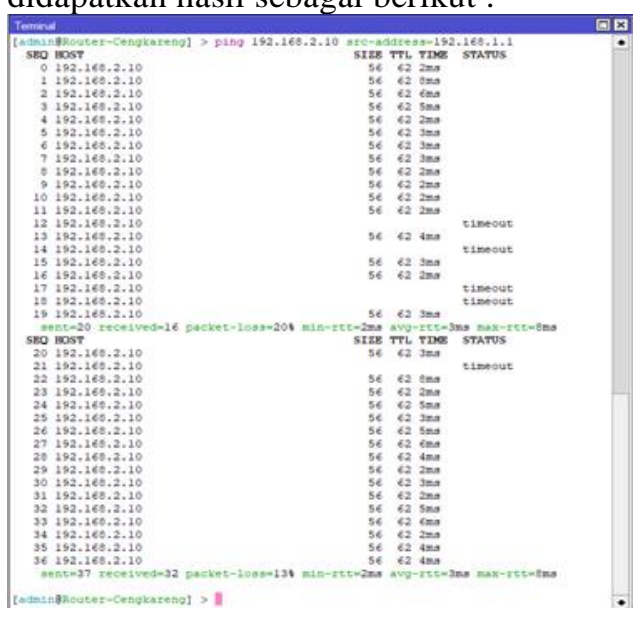

Sumber : Data Penelitian(2021)

Gambar 17. Ping User Site PIK

Dari gambar tersebut dijelaskan bahwa ketika tunnel FO mengalami down koneksi VPN masih dapat berjalan kembali secara otomatis dan proses intermitten hanya terjadi ketika proses pengecekan eoip tunnel. Dengan demikian network administrator tidak perlu mengkonfigurasikan link secara manual apabila salah satu link terkendala.

\section{6) Routing}

Dengan topologi dan konfigurasi seperti implementasi saat ini, table routing pada masingmasing site juga dapat dikelola dengan mudah dikarenakan routing terpusat pada concentrator. Pada setiap site hanya perlu mengkonfigurasikan routing ke global network VPN (192.168.0.0/16) dan diarahkan ke gateway bonding. Pengarahan routing ke masing-masing site berada pada sisi concentrator.

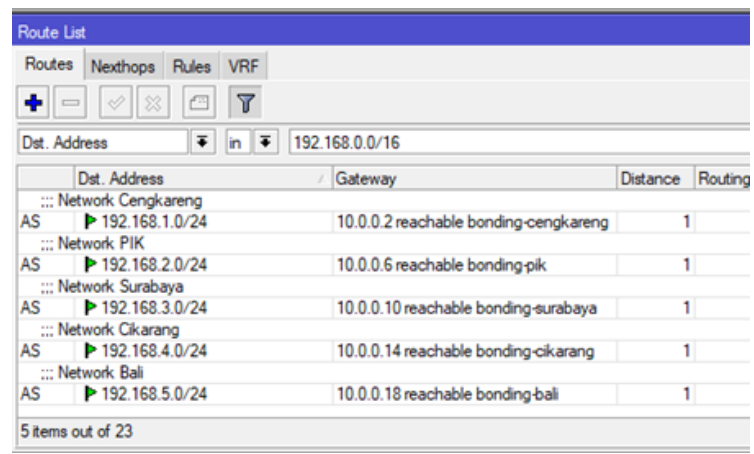

Sumber : Data Penelitian(2021)

Gambar 18. routing concentrator

Pada gambar tersebut dijelaskan bahwa table routing tersebut mengarahkan network address ke masing-masing bonding sehingga ketika router pada masing-masing site mengarahkan routing 192.168.0.0/16 ke router concentrator, router dapat memberikan informasi yang valid berdasarkan tabel routing tersebut.

\section{KESIMPULAN}

Setelah penulis membahas mengenai implementasi dan optimalisasi jaringan komputer menggunakan vpn concentrator dengan link aggregation (bonding) penulis mencoba menarik kesimpulan antara lain dengan menggunakan perangkat concentrator, jaringan vpn dapat lebih terkontrol baik dalam troubleshoot maupun penambahan site, tidak hanya itu dengan penerapan bonding jaringan vpn dapat lebih stabil dikarenakan kedua link dapat digunakan secara bersamaan sehingga meminimalisir kendala bottleneck pada salah satu link.

\section{REFERENSI}

Doni, F. R. (2019). IMPLEMENTASI MANAJEMEN BANDWIDTH PADA JARINGAN KOMPUTER DENGAN ROUTER MIKROTIK. Jurnal Sains dan Manajemen, 7(5), 52-57.

Doni, F. R., \& Lesmono, I. D. (2018). Mengubah Jarak dengan Penerapan Remote Access Menggunakan Team Viewer. Jurnal Kajian Ilmiah, 18(2), 129. https://doi.org/10.31599/jki.v18i2.234

Hidayatulloh, S., \& Wahyudin. (2019). Perancangan Wide Area Network (WAN) Dengan Teknologi Virtual Private Network (VPN). V(1), 7-14. https://doi.org/10.31294/jtk.v4i2

Kuswanto, H., \& Rahman, T. (2019). Failover Gateway Menggunakan Protokol Virtual Router Redundancy Protocol (VRRP) pada 
Mikrotik Router. Jurnal Sistem dan Teknologi Informasi (JUSTIN), 7(1), 60. https://doi.org/10.26418/justin.v7i1.29482

NIKMAH, K., \& Prihanto, A. (2017). Meningkatkan Troughputbandwidth Sekaligus Sebagai Jalur Failover Dengan Menggunakan Metode Bonding Pada Mikrotik. Jurnal Manajemen Informatika, 8(1).

Rahman, T., \& Rahman, F. A. (2020). Implementasi Automatic Uplink Power Control pada VSAT Single Channel per Carrier. 283-296.

Rahman, T., Sumarna, S., \& Nurdin, H. (2020). Analisis Performa RouterOS MikroTik pada Jaringan Internet. INOVTEK Polbeng - Seri Informatika, $\quad 5(1), \quad 178$. https://doi.org/10.35314/isi.v5i1.1308
Rifai, B., \& Supriyanto, E. (2017). Management System Failover Dengan Routing Dinamis Open Shortest Path First Dan Border Gateway Protocol. JITK (Jurnal Ilmu Pengetahuan Dan Teknologi Komputer), 3(1), 39-46. https://doi.org/https://doi.org/10.33480/jitk.v3i 1

Sobari, I. A. (2015). Rancangan Wireless Intrusion Detection System Menggunakan Snort. Jurnal Techno Nusa Mandiri, 12(1), 1-9.

Zuhri, M., \& Sobari, I. A. (2017). Optimalisasi Jaringan Wide Area Network Dengan Teknik Multiprotocol Label Switching. Prosiding SIMNASIPTEK,

190-194. http://seminar.bsi.ac.id/simnasiptek/index.php/ simnasiptek-2017/article/view/140 